\title{
A health economic analysis of combination therapy with infliximab plus elemental diet for moderately to severely active Crohn's disease
}

\author{
Shota Saito ${ }^{1}$, Utako Shimizu ${ }^{1}$, Zhang Nan $^{1}$, Junji Yokoyama ${ }^{2,3}$, Mayumi Watanabe ${ }^{4}$, \\ Kenshi Terajima ${ }^{4}$, Kohei Akazawa ${ }^{4^{*}}$ \\ ${ }^{1}$ Department of Medical Informatics and Statistics, Niigata University Graduate School of Medicine, Niigata, Japan \\ ${ }^{2}$ Department of Gastroenterology and Hepatology, Niigata University Medical and Dental Hospital, Niigata, Japan \\ ${ }^{3}$ Department of Endoscopy, Niigata University Medical and Dental Hospital, Niigata, Japan \\ ${ }^{4}$ Department of Medical Informatics, Niigata University Medical and Dental Hospital, Niigata, Japan; \\ *Corresponding Author: akazawa@med.niigata-u.ac.jp
}

Received 14 November 2013; revised 25 December 2013; accepted 8 January 2014

Copyright (C) 2014 Shota Saito et al. This is an open access article distributed under the Creative Commons Attribution License, which permits unrestricted use, distribution, and reproduction in any medium, provided the original work is properly cited. In accordance of the Creative Commons Attribution License all Copyrights (C) 2014 are reserved for SCIRP and the owner of the intellectual property Shota Saito et al. All Copyright (C) 2014 are guarded by law and by SCIRP as a guardian.

\section{ABSTRACT}

Although infliximab (IFX) is effective for inducing and maintaining remission in patients with Crohn's disease (CD), it is much more expensive than other treatments. The aim of this study is to evaluate the cost-effectiveness of several therapies, including IFX, for moderately to severely active CD. A Markov cohort model was constructed to simulate treatment effectiveness and costs. Transition probabilities, utilities, direct medical costs, and productivity costs were estimated using the results of published research. The primary effectiveness measurement was quality-adjusted life years (QALYs), as estimated by the 15D instrument. Expected effectiveness and total costs were calculated for a 10-year period using a yearly discount rate of $3 \%$ for QALYs and costs. Multiple one-way sensitivity analyses were performed by varying parameters that were likely to change QALYs and costs. As compared with nonbiologic therapy, therapy with IFX alone resulted in more QALYs and lower costs for the 10-year period. Combination therapy with IFX and elemental diet yielded an additional 0.252 QALYs at an additional cost of $\$ 18,522$ as compared with nonbiologic therapy over 10 years. The resulting incremental costeffectiveness ratio (ICER) of combination therapy vs nonbiologic therapy was $\$ 73,500 / Q A L Y$. Patient body weight was the most important factor for cost-effectiveness. In conclusion it was revealed that combination therapy with IFX plus elemental diet appears not to be a costeffective treatment for moderately to severely active $C D$.

\section{KEYWORDS}

Cost-Effectiveness; Crohn's Disease; Elemental Diet; Infliximab; Markov Model

\section{INTRODUCTION}

Crohn's disease (CD) is a chronic inflammatory disorder of the gastrointestinal tract, and the etiology is unknown. CD is characterized by relapsing and remitting episodes that progress to stricture, fistulas, and/or abscesses [1]. Onset of CD is typically between age 15 and 30 years. There is currently no established curative therapy for $\mathrm{CD}$, and the incidence of $\mathrm{CD}$ has been increasing in many countries $[2,3]$. In the United States and Canada, the number of CD patients has been estimated at 630,000, and in Europe between 23,000 and 41,000 new cases of CD are diagnosed annually [2]. In Japan, the incidence of CD was 5715 in 1989 and 30,891 in 2009, which represents a $440 \%$ increase during that period [3].

During the last decade, the advent of biologic therapy has significantly improved the clinical management of CD. Infliximab (IFX) has been shown to induce and maintain clinical remission in patients who do not respond to conventional drug therapies such as a corticosteroid and immunomodulators. The ACCENT1 trial revealed that scheduled maintenance therapy with IFX was 
significantly more effective than placebo in maintaining clinical remission in patients who had responded to an initial infusion [4]. However, the 1-year maintenance remission rate for 8-week scheduled maintenance therapy with IFX was estimated to be $29 \%$ to $38 \%$.

Some trials have investigated the efficacy of combination therapy with IFX plus elemental diet [5,6]. In prospective clinical trials, Yamamoto et al. showed that concomitant elemental diet during IFX maintenance therapy for patients with $\mathrm{CD}$ increased the 1-year maintenance remission rate from $67 \%$ for IFX maintenance therapy alone to $78 \%$, although the difference was not significant due to the small sample size [6].

With respect to direct medical costs, the high prevalence of CD results in a significant use of health services and is a considerable economic burden to society. On average, the annual total direct medical costs per patient for US patients with active CD were estimated at $\$ 18,022$ to $\$ 18,932$ in 2006 [7]. Moreover, direct medical costs increased with disease severity. Indeed, the costs for patients with severe CD are 17 times those of patients with mild disease [5]. In addition, progression of $\mathrm{CD}$ has a substantial adverse impact on an individual's productivity and quality of life [8]. Munkholm et al. reported that $15 \%$ to $24 \%$ of patients with CD work with some restrictions 5 years after diagnosis and that $15 \%$ of patients are unable to work 15 years after diagnosis [9].

Several studies have attempted to estimate the costeffectiveness of IFX in CD [10-14]. However, in our review of the literature, we found no study of the costeffectiveness of combined therapy with IFX and elemental diet. Thus, we assessed the cost-effectiveness of combination therapy with IFX plus elemental diet for moderately to severely active $\mathrm{CD}$ among non-responders to conventional drug therapies.

\section{METHODS}

\subsection{Model}

A Markov cohort model was designed to assess the cost-effectiveness of combination therapy with IFX plus elemental diet for moderately to severely active $\mathrm{CD}$. The model began in the initial state, and patients remained in the same state or transit to a possible subsequent state according to the transition probabilities at each cycle [15]. As shown in Figure 1, our model has nine Markov states: biologic remission, medical remission, mild disease, drugresponsive, drug-dependent, drug-refractory, surgery, surgical remission, and death. When the Markov cohort analysis was stopped at a projected endpoint, the total number of patient cycles for each state was divided by the person-years of the original cohort. Finally, the expected time and cost that each patient incurred in each state was added to estimate total quality-adjusted life

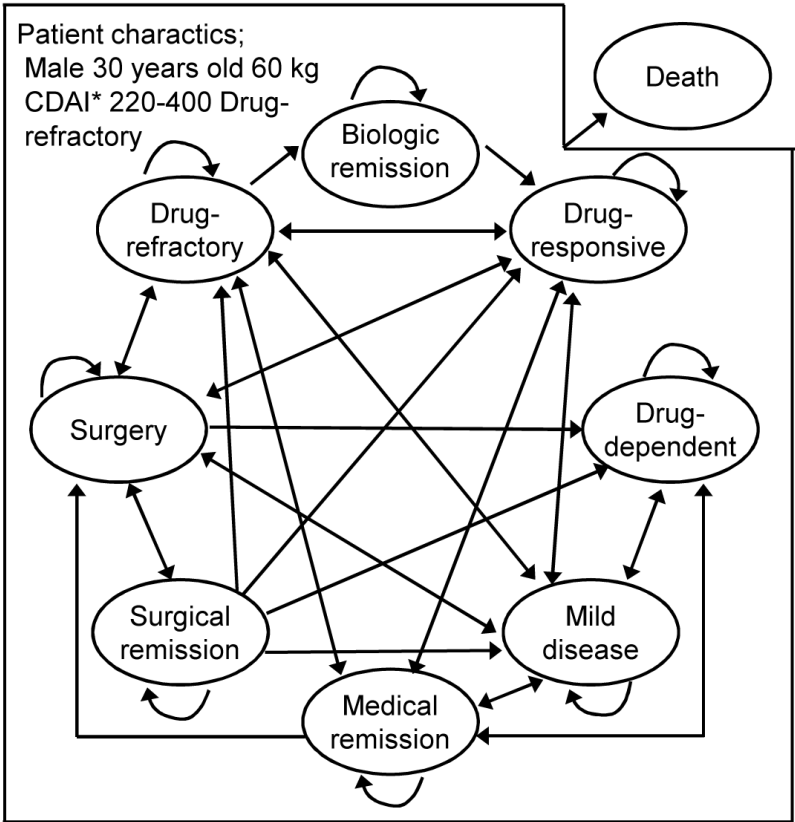

${ }^{*} \mathrm{CDAl}$, Crohn's diseases activity index

Figure 1. Structure of Markov cohort model for the cost-effectiveness analysis of treatments for Crohn's disease.

years (QALYs) and total cost. In our model, treatment with IFX alone, combination therapy with IFX plus elemental diet, and nonbiologic therapy were analyzed. Table 1 shows the definitions of the nine Markov states. They were defined by type of therapy used and by the magnitude of patient responses.

\subsection{Assumptions}

The model's base-case consisted of a hypothetical cohort of 30-year-old, $60-\mathrm{kg}$ males with moderately to severely active $C D$ that was refractory to conventional drug therapies. An age of 30 years was chosen as the entry age because $\mathrm{CD}$ onset typically occurs in the late teens to age 30 years [3].

All patients were assumed to have been diagnosed in the drug-refractory state and to have received intravenous infusion of IFX $5 \mathrm{mg} / \mathrm{kg}$ at week 0 . Initial response to IFX was defined as a Crohn's Disease Activity Index (CDAI) score of less than 150 points at week 2 after induction of the $5-\mathrm{mg} / \mathrm{kg}$ dose at baseline. We assumed that administration of IFX at 2 weeks and 6 weeks and every 8 weeks thereafter was continued for responders, i.e., those with a CDAI score less than 150 points.

Combination therapy consisted of consecutive administration of IFX (every 8 weeks) and an elemental diet (Elental; Ajinomoto Pharma Co., Tokyo, Japan). For the elemental diet, patients are given $1200 \mathrm{kcal} /$ day through a self-inserted tube and/or oral intake, which is known as the "half elemental diet" [16].

We assumed that serious adverse effects related to IFX 
Table 1. Definition of Markov model treatment states according to requirements for medication and surgery in patients with Crohn's disease.

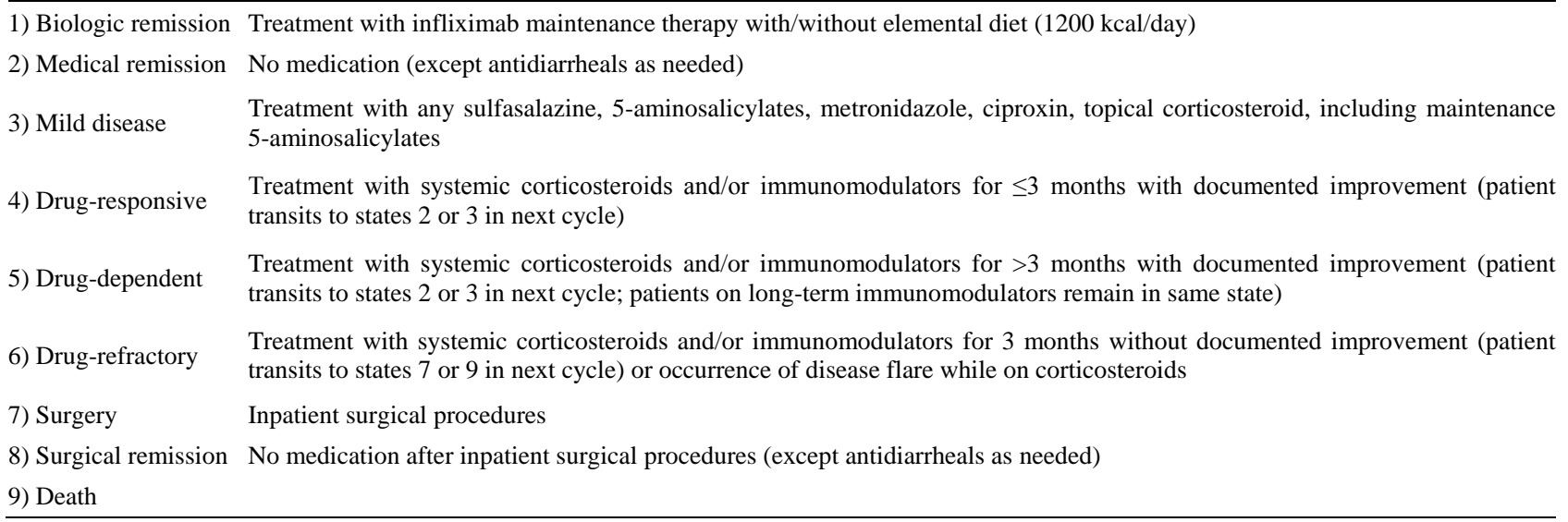

occurred at initial infusion (i.e., at week 0) and that patients who do not achieve remission at the initial administration of IFX or in consecutive administrations of IFX would not be offered retreatment with IFX and that they would have the same prognosis as those receiving nonbiologic therapy. Nonbiologic therapy included 5-aminosalicylic acid, antibiotics, immunomodulators, corticosteroids, and surgical treatment.

Some recent studies have suggested that survival rates in patients with CD are similar to those of the general population, after adjustment for age and gender $[17,18]$. Therefore, the current analysis assumed that mortality in CD patients was equivalent to that of the general population of Japan.

\subsection{Model Parameters}

Transition probabilities, utilities, and costs were derived from published studies (Table 2). The response rate of $56.4 \%$ for initial administration of IFX was based on research by Matsumoto et al. [19]. The maintenance remission rates for combination therapy and therapy with IFX alone were assumed to be $78.1 \%$ and $35.1 \%$, respectively, based on the findings of the ACCENT1 trial and Yamamoto et al. $[4,6]$. The rate of serious adverse effects associated with IFX was assumed to be $10.0 \%$, based on a systematic review of the literature, as previously reported [20]. The age-specific death rates for the general population were estimated from the 2008 abridged life table for Japan [21].

This study accounted for direct medical costs and productivity costs. Table 3 shows estimated direct medical costs and productivity costs at 3 months. Odes et al. [22] reported mean direct medical costs at 3 months for each health state of patients with CD. Then, we used these estimates of direct costs at 3 months and the transition probability for nonbiologic therapy. The productivity costs at different stages of CD were estimated using data from Mesterton et al. [23], who estimated the value of lost productivity using the human capital approach. According to this approach, the cost of reduced productivity in a patient is the amount employers would be willing to pay for the lost output. All costs were converted into US dollars using 2008 exchange rates reported by the Organization for Economic Co-operation and Development [24].

The primary effectiveness measure in this study was QALYs. Estimated values, which reflect quality of life for various CD health states, were assigned, and QALYs represents the sum of the values. The values for healthrelated quality of life, which varied from 0 (death) to 1 (perfect health), are taken from Mesterton et al. [23], who examined the estimated health-state preferences of CD patients $(n=420)$ using the 15D instrument in Sweden. We could not obtain the evidence of health-state preferences associated with IFX in CD. Therefore, a utility of 0.95 was assumed in this study. Other utilities were estimated from the work of Kaplan et al [11]. Costs and benefits were discounted at a rate of $3 \%$ per year in the base-case analysis [27].

\subsection{Cost-Effectiveness Analysis}

The overall costs and QALYs for patients with CD were calculated for a 10-year (3-month/cycle) follow-up period in the cost-effectiveness analysis. Cost-effectiveness was evaluated by using the incremental cost-effectiveness ratio (ICER), i.e., the ratio of increments in costs to increments in QALYs. An ICER lower than \$80,000 was defined as cost-effective, based on Kaplan's criteria [11]. In cost-effectiveness analysis, when a new protocol or treatment shows superior effectiveness and reduced cost, it is referred to as dominant.

First, we performed a base-case analysis incorporating the baseline parameters shown in Tables 2 and 3. Second, to assess the variability of the model results, multiple 
Table 2. Model input parameters.

\begin{tabular}{|c|c|c|c|}
\hline Parameter estimate & Value & Range & Reference \\
\hline \multicolumn{4}{|l|}{ Transition probabilities } \\
\hline IFX $^{*}$ initial response rate (2 weeks later) & 0.564 & $0.371-0.756$ & [19] \\
\hline \multicolumn{4}{|l|}{ Maintenance remission rate } \\
\hline \multicolumn{4}{|l|}{ IFX alone } \\
\hline Maintenance of remission at 1 year & 0.350 & $0.249-0.451$ & [4] \\
\hline 3-month rate & 0.769 & $0.706-0.819$ & \\
\hline \multicolumn{4}{|l|}{ Combination therapy } \\
\hline Maintenance of remission at 1 year $^{* *}$ & 0.781 & $0.638-0.924$ & {$[4,6]$} \\
\hline 3-month rate & 0.940 & $0.894-0.981$ & \\
\hline \multicolumn{4}{|l|}{ Adverse effect associated with IFX } \\
\hline Serious adverse effect & 0.100 & $0.036-0.160$ & [20] \\
\hline Death due to serious adverse effect & 0.004 & $0.000-0.010$ & [20] \\
\hline Mortality & & & \\
\hline Age-specific death rates & \multirow{2}{*}{\multicolumn{2}{|c|}{2008 life-table }} & [21] \\
\hline \multicolumn{2}{|l|}{ Nonbiologic therapy } & & \\
\hline Medical remission to mild disease & 0.054 & & [22] \\
\hline Medical remission to drug-responsive & 0.037 & & [22] \\
\hline Medical remission to drug-dependent & 0.011 & & [22] \\
\hline Medical remission to drug-refractory & 0.126 & & [22] \\
\hline Medical remission to surgery & 0.210 & & [22] \\
\hline Mild disease to medical remission & 0.033 & & [22] \\
\hline Mild disease to drug-responsive & 0.021 & & [22] \\
\hline Mild disease to drug-dependent & 0.010 & & [22] \\
\hline Mild disease to drug-refractory & 0.020 & & [22] \\
\hline Mild disease to surgery & 0.011 & & [22] \\
\hline Mild disease to death & 0.001 & & [22] \\
\hline Drug-responsive to medical remission & 0.167 & & [22] \\
\hline Drug-responsive to mild disease & 0.497 & & [22] \\
\hline Drug-responsive to drug-refractory & 0.134 & & [22] \\
\hline Drug-responsive to surgery & 0.020 & & [22] \\
\hline Drug-dependent to medical remission & 0.121 & & [22] \\
\hline Drug-dependent to mild disease & 0.379 & & [22] \\
\hline Drug-refractory to medical remission & 0.019 & & [22] \\
\hline Drug-refractory to mild disease & 0.041 & & [22] \\
\hline Drug-refractory to drug-responsive & 0.001 & & [22] \\
\hline Drug-refractory to surgery & 0.032 & & [22] \\
\hline Drug-refractory to death & 0.001 & & [22] \\
\hline Surgery to mild disease & 0.421 & & [22] \\
\hline Surgery to drug-responsive & 0.167 & & [22] \\
\hline Surgery to drug-dependent & 0.040 & & [22] \\
\hline Surgery to drug-refractory & 0.105 & & [22] \\
\hline Surgery to surgical remission & 0.180 & & [22] \\
\hline Surgical remission to mild disease & 0.039 & & [22] \\
\hline Surgical remission to drug-responsive & 0.014 & & [22] \\
\hline Surgical remission to drug-dependent & 0.002 & & {$[22]$} \\
\hline Surgical remission to drug-refractory & 0.005 & & {$[22]$} \\
\hline Surgical remission to surgery & 0.025 & & [22] \\
\hline Surgical remission to death & 0.002 & & [22] \\
\hline \multicolumn{4}{|l|}{ Quality of life utilities } \\
\hline Biologic remission & 0.95 & $0.92-0.98$ & \\
\hline Medical remission & 0.92 & & [23] \\
\hline Mild disease & 0.91 & & [23] \\
\hline Drug-responsive & 0.90 & & [23] \\
\hline Drug-dependent & 0.82 & & [23] \\
\hline Drug-refractory & 0.81 & & [23] \\
\hline Surgery & 0.77 & & [23] \\
\hline Surgical remission & 0.86 & & [11] \\
\hline Death & 0 & & \\
\hline \multicolumn{4}{|l|}{ Cost of drug and infusions (\$) } \\
\hline IFX (100-mg vial) & 580.94 & & [25] \\
\hline Administration of intravenous infusion & 193.00 & & [11] \\
\hline Elental (300-kcal pack) & 5.06 & & [26] \\
\hline Discount rate (\%) & 3 & $0-5$ & [27] \\
\hline
\end{tabular}

"IFX, Infliximab; ${ }^{* *}$ Base value was weighted mean. 
Table 3. Estimated cost at 3 months.

\begin{tabular}{cccc}
\hline Treatment states & Direct medical cost [22] & Productivity cost [23] & Total cost (\$) \\
\hline Biologic remission & & & 794 \\
IFX* alone & 3402 & 794 & 6196 \\
Combination therapy & 5244 & 794 & 1050 \\
Medical remission & 256 & 1584 & 2024 \\
Mild disease & 440 & 2374 & 5192 \\
Drug-responsive & 2818 & 3399 & 4834 \\
Drug-dependent & 1435 & 3765 & 4884 \\
Drug-refractory & 1119 & 13,357 & 23,076 \\
Surgery & 9719 & 794 & 1125 \\
Surgical remission & 331 &
\end{tabular}

*IFX, Infliximab.

one-way sensitivity analyses were conducted by varying the parameters for patient body weight, follow-up period, baseline age, response rate to initial administration of IFX, maintenance remission rate, serious adverse effect rate, and utility of biologic remission state.

All analyses were performed using the TreeAge Pro 2009 software program (TreeAge Software, Williamstown, MA, USA).

\section{RESULTS}

\subsection{Base-Case Analysis}

Costs, QALYs, and ICERs were calculated for each treatment strategy by using base-case analysis (Table 4). Therapy with IFX alone was superior to nonbiologic therapy in cost and QALY. Combination therapy yielded an additional 0.252 QALY at an additional cost of \$18,522 as compared with nonbiologic therapy. The resulting ICER of combination therapy versus nonbiologic therapy was estimated at $\$ 73,500 / \mathrm{QALY}$, which is lower than $\$ 80,000$. Therefore, combination therapy was cost-effective in comparison with nonbiologic therapy (Table 4). However, compared to IFX alone, the combination therapy would not to be perceived as a cost-effective strategy for moderately to severely active CD.

\subsection{Sensitivity Analysis}

Table 5 shows the results of sensitivity analysis. For all parameters except patient body weight, therapy with IFX alone resulted in more QALYs and lower cost. Therapy with IFX alone was the dominant strategy in comparison with nonbiologic therapy.

One-way sensitivity analyses confirmed that the results remained in the range of $\$ 46,698$ to $\$ 127,095$ at 10 years for combination therapy when patient body weight changed. This suggests that patient body weight is the most important factor in ICER for both combination therapy and therapy with IFX alone. The maintenance remission rate was also an important parameter for ICER in
Table 4. Base-case analysis in Markov model, by treatment strategy.

\begin{tabular}{cccc}
\hline & Nonbiologic therapy & IFX $^{*}$ alone & Combination therapy \\
\hline Cost $(\$)$ & 120,415 & 117,111 & 138,522 \\
Difference & & -3304 & 18,522 \\
QALYs $^{* *}$ & 7.458 & 7.608 & 7.71 \\
Difference & & 0.15 & 0.252 \\
ICERs $^{* * *}$ & & Dominant & 73,500 \\
\hline
\end{tabular}

"IFX, Infliximab; ${ }^{* *}$ QALYs, Quality-adjusted life years; ${ }^{* * *}$ ICER, Incremental cost-effectiveness ratio.

Table 5. Sensitivity analysis of important variables.

\begin{tabular}{|c|c|c|c|c|}
\hline \multirow{3}{*}{ Parameter } & \multicolumn{2}{|c|}{ Base-case Sensitivity } & \multicolumn{2}{|c|}{ Cost/QALYs $^{* *}\left(\mathrm{ICER}^{* * *}\right)$} \\
\hline & Estimate & Estimate & \multirow{2}{*}{ IFX $^{*}$ alone $^{\dagger}$} & Combination \\
\hline & & & & Therapy $^{\ddagger}$ \\
\hline \multirow{2}{*}{ Patient weight } & \multirow{2}{*}{$60 \mathrm{~kg}$} & $50 \mathrm{~kg}$ & Dominant & 46,698 \\
\hline & & $80 \mathrm{~kg}$ & 1260 & 127,095 \\
\hline \multirow{2}{*}{ Time horizon } & \multirow{2}{*}{10 years } & 5 years & Dominant & 68,584 \\
\hline & & 30 years & Dominant & 63,193 \\
\hline \multirow{2}{*}{ Baseline age } & \multirow{2}{*}{30 years } & 20 years & Dominant & 73,524 \\
\hline & & 40 years & Dominant & 73,079 \\
\hline \multirow{2}{*}{ Discount rate } & \multirow{2}{*}{$3 \%$} & $0 \%$ & Dominant & 74,377 \\
\hline & & $5 \%$ & Dominant & 72,925 \\
\hline \multirow{3}{*}{$\begin{array}{l}\text { IFX initial } \\
\text { response rate }\end{array}$} & \multirow{2}{*}{0.564} & 0.371 & Dominant & 87,855 \\
\hline & & 0.756 & Dominant & 67,415 \\
\hline & \multicolumn{4}{|c|}{ Maintenance remission rate } \\
\hline \multirow[t]{2}{*}{ IFX alone } & \multirow{2}{*}{0.350} & 0.249 & Dominant & 73,500 \\
\hline & & 0.451 & Dominant & 73,500 \\
\hline \multirow{2}{*}{$\begin{array}{l}\text { Combination } \\
\text { therapy }\end{array}$} & \multirow{2}{*}{0.781} & 0.638 & Dominant & 46,985 \\
\hline & & 0.924 & Dominant & 104,353 \\
\hline \multirow{2}{*}{$\begin{array}{l}\text { Serious adverse } \\
\text { effect rate }\end{array}$} & \multirow{2}{*}{0.100} & 0.036 & Dominant & 69,494 \\
\hline & & 0.160 & Dominant & 106,608 \\
\hline \multirow{2}{*}{$\begin{array}{c}\text { Mortality associated } \\
\text { with IFX }\end{array}$} & \multirow{2}{*}{0.004} & 0.000 & Dominant & 67,404 \\
\hline & & 0.010 & Dominant & 85,538 \\
\hline \multirow{2}{*}{$\begin{array}{c}\text { Biologic remission } \\
\text { utility }\end{array}$} & \multirow{2}{*}{0.95} & 0.92 & Dominant & 97,484 \\
\hline & & 0.98 & Dominant & 58,800 \\
\hline
\end{tabular}

${ }^{\dagger}$ Base-case = Dominant; ${ }^{\ddagger}$ Base-case $=73,500 ;{ }^{*}$ IFX, Infliximab; ${ }^{* *}$ QALYs, Quality-adjusted life years; ${ }^{* * *}$ ICER, Incremental cost-effectiveness ratio. 
combination therapy.

\section{DISCUSSION}

The results of our model indicate that combination therapy with IFX plus elemental diet was more cost-effective than nonbiologic therapies for moderately to severely active $\mathrm{CD}$, but more costly than IFX alone therapy.

Several studies have attempted to estimate the costeffectiveness of IFX for patients with CD [10-14]. Using appropriate assumptions regarding cost estimation and survival times for certain health states, a French lifetime cost-utility analysis of IFX reported that IFX therapy could be cost-effective in cases of relapse after first infusion only, although the ICER exceeded the predetermined threshold value according to their criteria for maintenance therapy [10]. In contrast, Lindsay et al. performed a cost-effectiveness analysis using a Markov model of hypothetical $60-\mathrm{kg}$ adult CD patients treated with IFX (5 $\mathrm{mg} / \mathrm{kg}$ every 8 weeks) based on the regimen in the ACCENT1 trial and found that IFX maintenance therapy was cost-effective for both active luminal and fistulizing CD [12]. They used an ICER threshold of $£ 30,000$ for the definition of cost-effective based on the criteria of the National Institute for Health and Clinical Excellence in the United Kingdom. As a result, the scheduled administration of IFX for maintaining remission was considered cost-effective in the treatment of CD in the United Kingdom.

Productivity cost is very important in evaluating costeffectiveness among patients with $C D$, because the onset of CD nearly always occurs in the third decade of life, when patients are in their prime. Therefore, our costeffectiveness analysis also included productivity costs and showed that therapy with IFX alone was dominant when compared with nonbiologic therapy.

Sensitivity analyses were performed by varying each base-case input parameter to assess variability of the model results. In one-way sensitivity analysis, a single variable is tested over its range of plausible values while all other variables remain constant. Body weight of CD patients was an important parameter affecting cost-effectiveness. Because of the weight-based dosing of IFX, patient weight had the greatest impact on the ICER, which increased to $\$ 127,095$ for combination therapy for an $80-\mathrm{kg}$ patient. The other variable that affected ICER was the maintenance remission rate for combination therapy. Use of IFX and Elental markedly increased as the maintenance remission rate rose.

Some studies have investigated the long-term efficacy of the elemental diet for CD. The elemental diet was useful in maintaining remission and significantly reduced clinical and endoscopic recurrence after resection in patients with CD $[16,28,29]$. In Japan, the elemental diet has been the first-line therapy for both active and quiescent $\mathrm{CD}$, in accordance with the guidelines established by the Ministry of Health, Labour and Welfare; 38.1\% and $27.2 \%$ of Japanese patients with CD were treated with an elemental diet and IFX therapy, respectively, in 13 university hospitals in 2009. Although the 1-year maintenance remission rates in CD patients treated with IFX maintenance therapy plus elemental diet versus IFX maintenance therapy alone were $78 \%$ and $67 \%$, respectively, the difference was not statistically significant [6]. However, the enhanced effectiveness of biologic therapy with concomitant elemental diet should reduce the need for further medications and thus spare patients from adverse effects associated with long-term drug use. Therefore, the effectiveness of combination therapy with IFX and elemental diet should be assessed in large-scale studies with longer follow-up periods.

Although IFX is effective for patients with moderately to severely active CD, loss of response to the $5-\mathrm{mg} / \mathrm{kg}$ dose can occur. In our analysis, initial responders who lost response after stopping IFX treatment were switched back to nonbiologic therapy without IFX. However, in clinical practice, these patients receive escalating doses of IFX (to $10 \mathrm{mg} / \mathrm{kg}$ ), a reduction in dose interval to every 4 or 6 weeks, or an alternative anti-TNF- $\alpha$ agent such as adalimumab or certolizumab pegol [8,30,31]. The IFX double-dosing and shortened dose-interval regimens were not included in this analysis because there are few data to support their efficacy.

Future cost-effectiveness analyses of CD are needed to determine the effectiveness of other biologics and regimens.

\section{CONCLUSION}

Combination therapy with IFX plus elemental diet appears not to be a cost-effective treatment for moderately to severely active CD.

\section{ACKNOWLEDGEMENTS}

This study was funded by a grant from the association of Platform for Clinical Information Statistical Analysis (NTT DATA Co., Tokyo, Japan). We also thank David Kipler for reviewing the language of the manuscript.

\section{REFERENCES}

[1] Colombel, J.F., Sandborn, W.J., Reinisch, W., Mantzaris, G.J., Kornbluth, A., Rachmilewitz, D., Lichtiger, S., D’Haens, G., Diamond, R.H., Broussard, D.L., Tang, K.L., van der Woude, C.J., Rutgeerts, P. and SONIC Study Group (2010) Infliximab, azathioprine, or combination therapy for Crohn's disease. New England Journal of Medicine, 362, 1383-1395.

http://dx.doi.org/10.1056/NEJMoa0904492 
[2] Lofts Jr., E.V. (2004) Clinical epidemiology of inflammatory bowel disease: Incidence, prevalence, and environmental influences. Gastroenterology, 39, 1504-1507. http://dx.doi.org/10.1053/j.gastro.2004.01.063

[3] Japan Intractable Diseases Research Foundation (2010) Intractable Diseases Information Center. http://www.nanbyou.or.jp

[4] Hanauer, S.B., Feagan, B.G., Lichternstein, G.R., Mayer, L.F., Schreiber, S., Colombel J.F., Rachmilewitz, D., Wolf, D.C., Olson, A., Bao, W., Rutgeerts, P. and ACCENT I Study Group (2002) Maintenance infliximab for Crohn's disease. The ACCENT 1 randomised trial. Lancet, 359, 1541-1549. http://dx.doi.org/10.1016/S0140-6736(02)08512-4

[5] Tanaka, T., Takahama, K., Kimura, T., Mizuno, T., Nagasaka, M., Iwata, K., Nakano, H., Muramatsu, M. and Takazoe, M. (2006) Effect of concurrent elemental diet on infliximab treatment for Crohn's disease. Journal of Gastroenterology and Hepatology, 21, 1143-1149. http://dx.doi.org/10.1111/j.1440-1746.2006.04317.x

[6] Yamamoto, T., Nakahigashi, M., Umegae, S. and Matsumoto, K. (2010) Prospective clinical trial: Enteral nutrition during maintenance infliximab in Crohn's disease. Journal of Gastroenterology, 45, 24-29. http://dx.doi.org/10.1007/s00535-009-0136-5

[7] Yu, A.P., Cabanilla, L.A. and Wu, E.Q. (2008) The costs of Crohn's disease in the United States and other Western countries: A systematic review. Current Medical Research and Opinion, 24, 319-328. http://dx.doi.org/10.1185/030079908X260790

[8] Lichtiger, S., Binion, D.G., Wolf, D.C., Present, D.H., Bensimon, A.G., Wu, E., Yu, A.P., Cardoso, A.T., Chao, J., Mulani, P.M., Lomax, K.G. and Kent, J.D. (2010) The CHOICE trial: Adalimumab demonstrates safety, fistula healing, improved quality of life and increased work productivity in patients with Crohn's disease who failed prior infliximab therapy. Alimentary Pharmacology \& Therapeutics, 32, 1228-1239.

http://dx.doi.org/10.1111/j.1365-2036.2010.04466.x

[9] Munkholm, P., Langholz, E., Davidsen, M. and Binder, V. (1995) Disease activity courses in a regional cohort of Crohn's disease patients. Scandinavian Journal of Gastroenterology, 30, 699-706. http://dx.doi.org/10.3109/00365529509096316

[10] Jaisson-Hot, I., Flourié, B., Descos, L. and Colin, C. (2004) Management for severe Crohn's disease: A lifetime cost-utility analysis. International Journal of Technology Assessment in Health Care, 20, 274-279. http://dx.doi.org/10.1017/S0266462304001084

[11] Kaplan, G.G., Hur, C., Korzenik. J. and Sands, B.E. (2007) Infliximab dose escalation VS. initiation of adalimumab for loss of response in Crohn's disease: A costeffectiveness analysis. Alimentary Pharmacology \& Therapeutics, 26, 1509-1520.

http://dx.doi.org/10.1111/j.1365-2036.2007.03548.x

[12] Lindsay, J., Punekar, Y.S., Morris, J. and Chung-Faye, G. (2008) Health-economic analysis: Cost-effectiveness of scheduled maintenance treatment with infliximab for Crohn's disease-Modeling outcomes in active luminal and fistulizing disease in adults. Alimentary Pharmacology \& Therapeutics, 28, 76-87.

http://dx.doi.org/10.1111/j.1365-2036.2008.03709.x

[13] Bodger, K., Kikuchi, T. and Hughes, D. (2009) Costeffectiveness of biological therapy for Crohn's disease: Markov cohort analyses incorporating United Kingdom patient-level cost data. Alimentary Pharmacology \& Therapeutics, 30, 265-274. http://dx.doi.org/10.1111/j.1365-2036.2009.04033.x

[14] Punekar, Y.S., Sunderland, T., Hawkins. N. and Lindsay, J. (2010) Cost-effectiveness of Scheduled Maintenance Treatment with Infliximab for Pediatric Crohn's Disease. Value Health, 13, 188-195. http://dx.doi.org/10.1111/j.1524-4733.2009.00658.x

[15] Nakamura, J., Toyabe, S.I., Aoyagi, Y. and Akazawa, K. (2008) Economic impact of extended treatment with peginterferon $\alpha$-2a and ribavirin for slow hepatitis $\mathrm{C}$ virologic responder. Journal of Viral Hepatitis, 15, 293-299. http://dx.doi.org/10.1111/j.1365-2893.2007.00943.x

[16] Takagi, S., Utsunomiya, K., Kuriyama, S., Yokoyama, H., Takahashi, S., Iwabuchi, M., Takahashi, H., Takahashi, S., Kinouchi, Y., Hiwatashi, N., Funayama, Y., Sasaki, I., Tsuji, I. and Shimosegawa, T. (2006) Effectiveness of an "half elemental diet” as maintenance therapy for Crohn's disease: A randomized-Controlled trial. Alimentary Pharmacology \& Therapeutics, 24, 1333-1340. http://dx.doi.org/10.1111/j.1365-2036.2006.03120.x

[17] Jess, T., Loftus, E.V., Harmsen, W.S., Zinsmeister A.R., Tremaine, W.J., Melton III, L.J., Munkholm, P. and Sandborn, W.J. (2006) Survival and cause specific mortality in patients with inflammatory bowel disease: A long term outcome study in Olmsted Country, Minnesota, 19402004. Gut, 4, 621-630.

[18] Lichtenstein, G.R., Feagan, B.G., Cohen, R.D., Salzberg, B.A., Diamond, R.H., Chen, D.M., Pritchard, M.L. and Sandborn W.J. (2006) Serious infections and mortality in association with therapies for Crohn's Disease: TREAT registry. Clinical Gastroenterology and Hepatology, 4, 621-630. http://dx.doi.org/10.1016/j.cgh.2006.03.002

[19] Matsumoto, T., Iida. M., Motoya, S., Haruma, K., Suzuki, Y., Kobayashi, K., Ito, H., Miyata M., Kusunoki, M., Chiba, T., Yamamoto, S. and Hibi, T. (2008) Therapeutic efficacy of infliximab on patients with short duration of Crohn's disease: A Japanese multicenter survey. Diseases of the Colon \& Rectum, 51, 916-923. http://dx.doi.org/10.1007/s10350-008-9241-4

[20] Siegel, C.A., Hur, C., Korzenik, J.R. and Sands, B.E. (2006) Risk and benefits of infliximab for the treatment of Crohn's disease. Clinical Gastroenterology and Hepatology, 4, 1017-1024. http://dx.doi.org/10.1016/j.cgh.2006.05.020

[21] Tokyo Stastics and Information Department, Minister's Secretariat, Ministry of Health, Labour, and Welfare (2010) Abridged life Table for Japan, 2008.

http://www.mhlw.go.jp/toukei/saikin/hw/life/life08/index. $\underline{\mathrm{html}}$

[22] Odes, S., Vardi, H., Friger, M., Esser, D., Wolters, F., Moum, B., Waters, H., Elkjaer, M., Bernklev, T., Tsianos, E., O’Morain, C., Stockbrügger, R., Munkholm, P. and 
Langholz, E. (2010) Clinical and economic outcomes in a population-based European cohort of 948 ulcerative colitis and Crohn's disease patients by Markov analysis. Alimentary Pharmacology \& Therapeutics, 31, 735-744. http://dx.doi.org/10.1111/j.1365-2036.2009.04228.x

[23] Mesterton, J., Jönsson, L., Almer, S.H., Befrits, R., FriisLiby, I. and Lindgren, S. (2009) Resource use and societal costs for Crohn's disease in Sweden. Inflammatory Bowel Diseases, 15, 1882-1890. http://dx.doi.org/10.1002/ibd.20939

[24] Organization for Economic Co-Operation and Development (2008) OECD economic outlook No. 87 annex tables-Table of contents 2008.

http://www.oecd.org/eco/outlook/economicoutlookannext ables.htm

[25] Yu, A.P., Johnson, S., Wang, S.T., Atanasov, P., Tang, J., Wu, E., Chao, J. and Mulani, P.M. (2009) Cost utility of adalimumab versus infliximab maintenance therapies in the United States for moderately to severely active Crohn's disease. Pharmacoeconomics, 27, 609-621. http://dx.doi.org/10.2165/11312710-000000000-00000

[26] Ministry of Health, Labour and Welfare (2010) Various Information of Medical Fee. http://www.iryohoken.go.jp/shinryohoshu/

[27] Weinsteins, M.C., Siegel, J.E., Gold, M.R., Kamlet, M.S. and Russell, L.B. (1996) Recommendations of the panel on cost-effectiveness in health and medicine. JAMA, 276, 1253-1258. http://dx.doi.org/10.1001/jama.1996.03540150055031

[28] Verma, S., Kirkwood, B., Brown, S., Brown, S. and Giaffer, M.H. (2000) Oral nutritional supplementation is effective in the maintenance of remission in Crohn's disease. Digestive and Liver Disease, 32, 769-774. http://dx.doi.org/10.1016/S1590-8658(00)80353-9

[29] Yamamoto, T., Nakahigashi, M., Umedae, S., Kitagawa, T. and Matsumotom K. (2007) Impact of long-term enteral nutrition on clinical and endoscopic recurrence after resection for Crohn's disease: A prospective, non-randomised, parallel, controlled study. Alimentary Pharmacology \& Therapeutics, 25, 67-72. http://dx.doi.org/10.1111/j.1365-2036.2006.03158.x

[30] Schreiber, S, Khaliq-Kareemi, M., Lawrance, I.C., Thomsen, O.Ø. and Hanauer, S.B., McColm, J., Bloomfield, R., Sandborn, W.J., PRECISE 2 study investigators (2007) Maintenance therapy with certlizumab pegol for Crohn's disease. New England Journal of Medicine, 357, 239-250. http://dx.doi.org/10.1056/NEJMoa062897

[31] Kopylov, U., Mantzaris, G.J., Katsanos, K.H., Reenaers, C., Ellul, P., Rahier, J.F., Israeli, E., Lakatos, P.L., Fiorino, G., Cesarini, M., Tsianos, E.V., Louis, E. and Ben-Horin, S. (2011) The efficacy of shortening the dosing interval to once every six weeks in Crohn's patients losing response to maintenance dose of infliximab. Alimentary Pharmacology \& Therapeutics, 33, 349-357. http://dx.doi.org/10.1111/j.1365-2036.2010.04523.x 